\title{
MHD Unsteady Free Convective Visco-Elastic Fluid Flow over a Radiative Vertical Porous Plate with Dufour Effects in Presence of Chemical Reaction
}

\author{
Rita Choudhury \\ Department of Mathematics \\ Gauhati university-14
}

\author{
Hillol Kanti Bhattacharjee \\ Department of Mathematics \\ Gauhati university-14
}

\begin{abstract}
The analysis on the unsteady two-dimensional incompressible visco-elastic MHD free convective fluid flow over a radiative vertical porous plate with Dufour effects in presence of chemical reaction has been presented. A uniform magnetic field acts perpendicular to the porous surface. The Rosseland approximation has been used to describe the radiative heat flux in energy equation and the influence of various flow parameters involved in the solution are described both numerically and physically to understand the physics of the problem. It is observed that the flow field is considerably affected by the visco-elastic parameter in comparison with Newtonian phenomena in presence of other physical variables. Possible applications of the present study include MHD propulsion thermo fluid dynamics, boundary layer in aerodynamics, chemical engineering etc.
\end{abstract}

\section{Keywords}

MHD , Dufour effect, chemical reaction, Walter's liquid.

\section{Mathematics Subject Classification: 76A05, 76A10}

\section{INTRODUCTION}

The analysis of MHD viscous fluid flows in porous media have been extensively examined during the last several decades due to many practical applications which can be modeled or approximated as transport phenomena in porous media. Coupled heat and mass transfer in boundary layer flow over vertical porous plate play vital role in many engineering, industrial applications such as plasma studies, cooling of nuclear reactions, crystal growth and the manufacture of plastic film and article fiber materials. Combined heat and mass transfer problems with chemical reaction are of important in many processes and have, therefore, received a considerable amount of attention in recent years. When heat and mass transfer occur simultaneously between the fluxes, the driving potential is more intricate nature, as energy flux can be generated not only by temperature gradients but by composition gradients as well. The energy flux caused by a composition gradient is added the Dufour or diffusion thermo effect. This effect has gained considerable interest in both Newtonian and non-Newtonian convective heat and mass transfer problems. A comprehensive review of the studies of convective heat transfer mechanism through porous media has been made by Neild and Bejan [1]. Combined heat and mass transfer problems with chemical reaction are of importance in many processes. On the diffusion of a chemically reaction, heat and mass transfer on non-linear MHD laminar boundary layer flow over a wedge with suction or injection. Raptis et al
[4] have investigated the viscous flow over a non-linearly stretching sheet in the presence of chemical reaction and magnetic field. Mangchun et al [5] have developed a two dimension mathematical model to simulate the coupled heat and mass transfer in a porous medium undergoing a strong endothermic chemical reaction. Effects of chemical reaction, heat and mass transfer along a wedge with heat source and concentration in the presence of suction and injection, on MHD flow over a vertical stretching surface with heat source and thermal stratification effects has been studied by Kandasamy et al [6]. Ibraham et al [7] have analyzed the effect of the chemical reaction and radiation absorption on the unsteady free convective flow past a semi-infinite vertical permeable moving plate with heat source and suction. Rajesh et al. [8] have studied the chemical reaction and radiation effects on MHD flow past an infinite vertical plate with variable temperature. Diffusion thermo and radiation effects on MHD free convective heat and mass transfer flow past an infinite vertical plate in the presence of a chemical reaction of first order has been studied by Raveendra Babu et al. [9].

Again many rheological models have been proposed to describe the mechanical behaviours of visco-elastic fluids. This type of fluid exhibits both the viscous and elastic characteristics. The analysis of chemical reaction, heat and mass transfer in MHD visco-elastic fluid flows has attracted numerous scientists and engineers for the last served decades because of its fascination and importance in various technological devices and understanding the diverse cosmic phenomena and power generation of energy. This study helps to solve many biological problems. Considering the model of visco-elastic fluid, many scientists have solved problems of engineering interests viz. Saxena and Dubey [10], Choudhury and Mahanta (2012) [11], Choudhury and Das(2012) [12], Choudhury and Purkayastha(2012) [13], Choudhury and Dey $\left(2012_{1}, 2012_{2}\right)$ [14],[15] , Choudhury and Dhar [16]

In this study, an attempt has been made to investigate the diffusion thermo(Dufour effect) and radiative effects on MHD, unsteady, free convective flow of visco-elastic fluid characterized by Walters liquid (Model $B^{\prime}$ ) over a stretching porous surface embedded in porous medium with chemical reaction. The flow field is influenced by heat and mass transfer. Analytical solution are obtained and some results are discussed graphically to understand the physics of the problem.

The constitutive equation for Walters liquid $\left(\right.$ Model $\mathrm{B}^{\prime}$ ) is

$\sigma_{\mathrm{ik}}=-\mathrm{pg}_{\mathrm{ik}}+\sigma_{\mathrm{ik}}^{\prime}$ 
$\sigma^{\prime i k}=2 \eta_{0} \mathrm{e}^{\mathrm{ik}}-2 \mathrm{k}_{0} \mathrm{e}^{\mathrm{ik}}$

where $\sigma^{\mathrm{ik}}$ is the stress tensor, $\mathrm{p}$ is isotropic pressure, $g_{\mathrm{ik}}$ is the metric tensor of a fixed co-ordinate system $x^{i}, v_{i}$ is the velocity vector, the contravarient form of $\mathrm{e}^{\prime \mathrm{ik}}$ is given by

$\mathrm{e}^{\prime \mathrm{ik}}=\frac{\partial \mathrm{e}^{\mathrm{ik}}}{\partial \mathrm{t}}+\mathrm{v}^{\mathrm{m}} \mathrm{e}^{\mathrm{i}}{ }_{, \mathrm{m}}-\mathrm{v}^{\mathrm{k}}{ }_{\mathrm{m}} \mathrm{e}^{\mathrm{im}}-\mathrm{v}^{\mathrm{i}}{ }_{\mathrm{m}} \mathrm{e}^{\mathrm{mk}}{ }_{(1.2)}$

It is the convected derivative of the deformation rate tensor $\mathrm{e}^{\mathrm{ik}}$ defined by

$2 \mathrm{e}^{\mathrm{ik}}=\mathrm{v}_{\mathrm{i}, \mathrm{k}}+\mathrm{v}_{\mathrm{k}, \mathrm{i}}$

Here $\eta_{0}$ is the limiting viscosity at the small rate of shear which is given by

$$
\eta_{0}=\int_{0}^{\infty} \mathrm{N}(\tau) \mathrm{d} \tau \text { and } \mathrm{k}_{0}=\int_{0}^{\infty} \tau \mathrm{N}(\tau) \mathrm{d} \tau
$$

$\mathrm{N}\left({ }^{\tau}\right)$ being the relaxation spectrum. This idealized model is a valid approximation of Walters liquid (Model $\mathrm{B}^{\prime}$ ) taking very short memories into account so that terms involving

$$
\int_{0}^{\infty} t^{n} N(\tau) d \tau, n \geq 2
$$

have been neglected.

\section{MATHEMATICAL FORMULATION}

The region of unsteady two dimensional flow of an electrically conducting visco-elastic fluid, along an infinite vertical porous plate has been analyzed in presence of chemical reaction. A uniform magnetic field B0 is applied normal to the plate. Here the mechanism of heat and mass transfer in connection with Dufour effects are studied. The x'-axis is taken along the plate vertically upward to the opposite direction of gravity and the $y^{\prime}$ axis is taken normal to the plate. Let $\mathrm{u}^{\prime}$ and $\mathrm{v}^{\prime}$ be the velocity components in $\mathrm{x}^{\prime}$ and $\mathrm{y}^{\prime}$ directions respectively. Under the above assumptions as well as Rosseland approximations the flow is governed by the following set of equations:

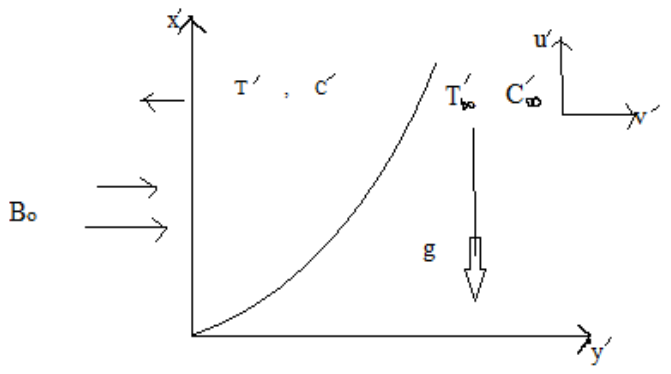

Figure (A):- Flow configuration and co-ordinate system.

Equation of continuity:

$$
\frac{\partial v^{\circ}}{\partial y}=0
$$

$=>v^{*}=$ constant $=-v_{0 x} \quad v_{0}>0$

Equation of motion:

$$
\begin{aligned}
& \frac{\partial u^{s}}{\partial t}+v \frac{\partial u^{s}}{\partial y}=\frac{\eta_{0}}{\rho} \frac{\partial^{2} u^{s}}{\partial y^{2}}-\frac{k_{0}}{\rho}\left(\frac{\partial^{2} u^{s}}{\partial t^{\prime} \partial y^{2}}+v^{s} \frac{\partial^{\mathrm{a}} u}{\partial y^{2}}\right) \\
& +g \beta\left(T^{s}-T_{\infty}^{s}\right)+g \beta^{s}\left(C^{s}-C_{\infty}^{s}\right)-\frac{\sigma B_{0}^{2} u^{*}}{\rho}-\frac{v}{K} u^{s}
\end{aligned}
$$

Energy equation:

$\frac{\partial T^{\sigma}}{\partial t}+v^{\prime} \frac{\partial T^{\sigma}}{\partial y}=\frac{k}{\rho c_{P}} \frac{\partial^{2} T^{\sigma}}{\partial y^{2}}-\frac{1}{\rho c_{P}} \frac{\partial q_{Y}^{\sigma}}{\partial y}+\frac{D_{m} K_{T}}{c_{g} C_{P}} \frac{\partial^{2} c^{\sigma}}{\partial y^{2}}$

Concentration equation;

$\frac{\partial c^{*}}{\partial t}+v^{s} \frac{\partial c^{*}}{\partial y}=D_{m} \frac{\partial^{2} c^{*}}{\partial y^{2}}-K_{1}\left(c^{s}-c_{c o s}^{s}\right)$

and $\frac{\partial p^{p}}{\partial y}=0=>p^{s}=$ contant

with relevant boundary conditions :

$\left.\begin{array}{lll}u^{*}=U_{v} & v^{*}=v(t), T^{*}=T_{w}, c^{*}=c_{w} \text { at } y=0 \\ u^{*}=0, \quad T^{\prime}=T_{\infty}, \quad c^{*}=c_{\infty} & \text { as } y \rightarrow \infty\end{array}\right\}$

The non-dimensional parameters are :

$y=\frac{y U}{v}, t=\frac{t U^{2}}{v}, u=\frac{u^{*}}{U}, \quad \theta=\frac{T^{*}-T_{\infty}}{T_{w}^{*}-T_{\infty}}$,

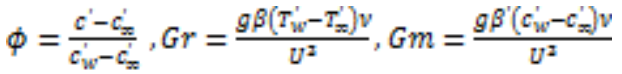

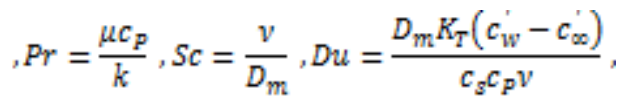

$M=\frac{\sigma B_{5}^{2} v}{\rho U^{2}}, F=\frac{4 f^{x}}{\rho c_{g} U^{2}}, K=\frac{K^{x} U_{0}^{2}}{v^{2}}, K r=\frac{w K_{2}}{U^{2}}$,

$k=\frac{k_{0} U^{2}}{\rho v^{2}} \quad{ }_{n} L=\frac{v_{0}}{U}$

where $\mathrm{Gr}$ is the Grashof number for heat transfer, $\mathrm{Gm}$ is the Grashof number for mass transfer, ${ }^{B_{0}}$ is the magnetic field, ${ }^{\beta^{\circ}}$ is the volumetric co-efficient of expansion for mass transfer, ${ }^{\beta}$ is the co-efficient of volume expansion for heat transfer, $g$ is the acceleration due to gravity ${ }^{T}$ and $T_{\infty}^{\infty}$ are the temperature of the fluid inside the thermal boundary layer and the fluid temperature in the free stream respectively, while $c$ and $C_{\infty}$ are the corresponding concentrations, $D_{m}$ is the co- 
efficient of mass diffusivity, $K_{r}$ is chemical reaction parameter, $\mathrm{K}$ is the permeability parameter.

Introducing the non-dimensional parameters in the equations (2.2), (2.3), (2.4), we get

$$
\begin{gathered}
\frac{\partial u}{\partial t}-L \frac{\partial u}{\partial y}=\frac{\partial^{2} u}{\partial y^{2}}-k\left(\frac{\partial^{a} u}{\partial t \partial y^{2}}-L \frac{\partial^{a} u}{\partial y^{2}}\right)+G r \theta \\
+G m \phi-\left(M+\frac{1}{K}\right) u
\end{gathered}
$$

$\frac{\partial \theta}{\partial t}-L \frac{\partial \theta}{\partial y}=\frac{1}{\operatorname{Pr}} \frac{\partial^{2} \theta}{\partial y^{2}}-F \theta+D u \frac{\partial^{2} \phi}{\partial y^{2}}$

$\frac{\partial \phi}{\partial t}-L \frac{\partial \phi}{\partial y}=\frac{1}{S c} \frac{\partial^{2} \phi}{\partial y^{2}}-K r \phi$

where $k=\frac{\eta_{0}}{\rho}$ is the visco-elastic parameters

subject to boundary conditions :

$u=1, \theta=1, \phi=1$ at $y=0$

$u=0, \theta=0, \phi=0$ as $y \rightarrow \infty$

\section{METHOD OF SOLUTION}

We assume the solutions of the non-linear partial differential equations (2.7) to (2.9) of the following form $u=u_{0}(y)+k u_{1}(y)$

$$
\theta=\theta_{0}(y)+k \theta_{1}(y)
$$

$$
\phi=\phi_{0}(y)+k \phi_{1}(y)
$$

Here we take $k$ to be very small as $k<<1$ ( as due to small shear rate $k$ is very small)

Using (3.1) in the equation (2.7), (2.8) and (2.9), equating the co-efficient of like powers of $k$ and neglecting higher powers of $k$, we get,

$$
\begin{aligned}
& u_{0}^{s}+L u_{0}^{s}-\left(M+\frac{1}{K}\right) u_{0}=-G r \theta_{0}-G m \phi_{0} \\
& u_{1}^{s}+L u_{1}^{s}-\left(M+\frac{1}{K}\right) u_{1}=-G r \theta_{1}-G m \phi_{1}-L u_{0}^{m} \\
& \theta_{0}^{w}+\operatorname{Pr} L \theta_{0}^{s}-\operatorname{PrF} \theta_{0}=-\operatorname{Pr} D u \phi_{0}^{a} \\
& \theta_{1}^{\alpha r}+\operatorname{PrL} \theta_{1}^{\alpha}-\operatorname{PrF} \theta_{1}=-\operatorname{PrD} u \phi_{1}^{\alpha r} \\
& \phi_{0}^{w}+\operatorname{LSc} \phi_{0}^{s}-\operatorname{ScKr} \phi_{0}=0 \\
& \phi_{1}^{a r}+L S c \phi_{1}-S c K r \phi_{1}=0
\end{aligned}
$$

The modified boundary conditions are :

$$
\begin{aligned}
& u_{0}=1, \theta_{0}=1_{s} \phi_{0}=1 \\
& u_{1}=0, \theta_{1}=0, \phi_{1}=0 \text { s at } y=0 \\
& \text { and } u_{0}=0{ }_{0} \theta_{0}=0, \phi_{0}=0 \\
& u_{1}=0{ }_{x} \theta_{1}=0, \phi_{1}=0 \text { s at } y \rightarrow \infty
\end{aligned}
$$

Solving equations (3.6) and (3.7) and using boundary conditions (3.8) we get,

$$
\begin{aligned}
& \phi_{0}=e^{-\alpha_{2} y} \\
& \phi_{1}=0
\end{aligned}
$$

The solutions of the equation (3.4) and (3.5) subject to the boundary conditions (3.8) are given by

$$
\begin{aligned}
& \theta_{0}=A_{1} e^{-a_{4} y}-A_{2} e^{-a_{2} y} \\
& \theta_{1}=0
\end{aligned}
$$

Solving equations (3.2) and (3.3) and using boundary conditions (3.8) we get,

$$
\begin{aligned}
& u_{0}=e^{-\alpha_{2} y}+A_{5} e^{-\alpha_{2} y}-A_{2} e^{-\alpha_{4} y}+A_{4} e^{-\alpha_{2} y} \\
& u_{1}=A_{6} e^{-\alpha_{2} y}+A_{7} y e^{-\alpha_{2} y}-A_{8} e^{-a_{4} y}+A_{9} e^{-\alpha_{2} y}
\end{aligned}
$$

The constants are obtained but not presented here for the sake of brevity.

\section{RESULT AND DISCUSSION}

The velocity profile for the fluid flow is given as

$$
\begin{gathered}
u=e^{-\alpha_{2} y}+A_{5} e^{-a_{2} y}-A_{2} e^{-a_{4} y}+A_{4} e^{-a_{2} y}+k\left(A_{6} e^{-a_{2} y}\right. \\
\left.+A_{7} y e^{-\alpha_{2} y}-A_{9} e^{-a_{4} y}+A_{9} e^{-\alpha_{2} y}\right)
\end{gathered}
$$

The non-dimensional shearing stress at the plate is given by

$$
\begin{aligned}
& \sigma=\left(-\alpha_{6}-A_{5} \alpha_{6}+A_{2} \alpha_{4}-A_{4} \alpha_{2}\right) \\
& +k\left[\left(-A_{6} \alpha_{6}+A_{7}+A_{8} \alpha_{4}-A_{9} \alpha_{2}\right)+L\left(\alpha_{6}^{2}+A_{5} \alpha_{6}^{2}-\right.\right. \\
& \left.\left.A_{3} \alpha_{4}^{2}+A_{4} \alpha_{2}^{2}\right)\right] \quad(4.2)
\end{aligned}
$$

The non-dimensional rate of heat transfer in the form of Nusselt number is given by

$$
N_{u}=\left(\frac{\partial T}{\partial y}\right)_{y=0}
$$

The non-dimensional rate of mass transfer in terms of Sherwood number is given by

$$
S_{\mathfrak{h}}=\left(\frac{\partial C}{\partial y}\right)_{y=\mathbb{a}}
$$

The constants are obtained but not given due to brevity. 
The objective of the present paper is to study the MHD , unsteady, free convective visco-elastic fluid flow over a radiative vertical porous plate with Dufour effects in presence of chemical reaction. The mechanism of heat and mass transfer is also considered.

To understand the physics of the problem the fluid velocity $u$ is depicted against $y$ in figures 1 to 10 for different values of Prandtl number Pr, Grashof number for heat transfer Gr, Grashof number for mass transfer Gm, Magnetic parameter M, Radiation parameter F, Dufour number Du, Chemical reaction $\mathrm{Kr}$, Schmidt number Sc and visco-elastic parameter $k$. The numerical calculations are carried out for Permeability parameter $\mathrm{K}=1$ and $\mathrm{L}=1$

For externally cooled plate $(\mathrm{Gr}>0)$, the fluid velocity $u$ (figure 1,2 ) exhibits accelerating trend with the growing effect of visco-elasticity. It is also noticed that the velocity field enhances near the plate $\mathrm{y}=0$ and then diminishes with the increasing value of $y$ in both Newtonian and non-Newtonian cases.

The variation of the Grashof number for mass transfer Gm ( figures 1,3 ) reveals that the fluid velocity changes its trend when $\mathrm{Gm}$ decreases (figure 1,3 ) the rising effect of viscoelasticity shows a accelerating trend and the decelerating trend in comparison with Newtonian case.

The variation of the magnetic parameter in (figures 1,4), radiation parameter $\mathrm{F}$ ( figures 1,5 ), the Dufour number $\mathrm{Du}$ (figures 1,6), the chemical reaction $\mathrm{Kr}$ ( figures 1,7), the Schmidt number ( figure 1,8), the Prandtl number ( figure 1, 9), do not alter the pattern of fluid velocity in both Newtonian and non-Newtonian fluid flow mechanism. Also, the growth of visco-elasticity reveals the rising trend of the fluid velocity in the fluid flow region in all the cases.

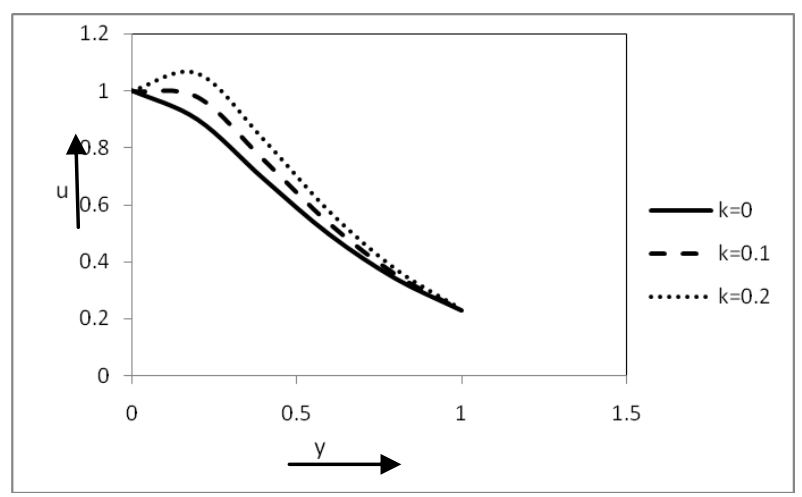

Figure 1: Variation of $u$ against $y$

$\mathrm{Pr}=5, \mathrm{Gr}=5, \mathrm{Gm}=8, \mathrm{M}=2, \mathrm{~F}=0.5, \mathrm{Du}=0.03, \mathrm{~K}=1, \mathrm{Kr}=0.6$, $\mathrm{Sc}=3$.

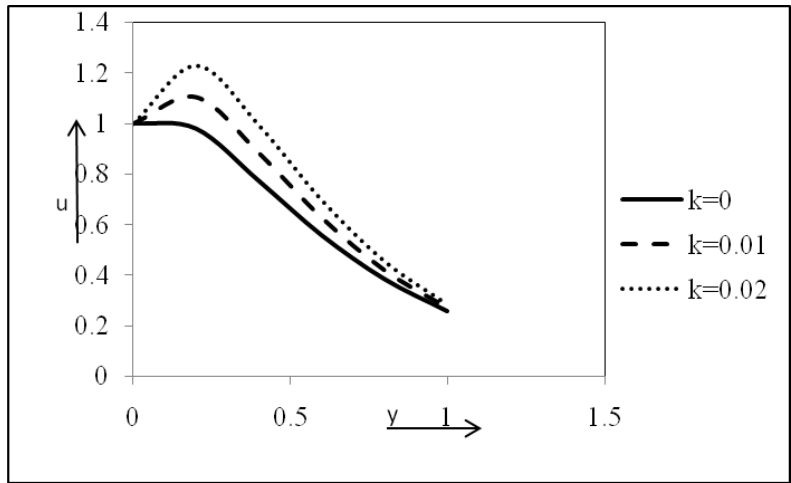

Figure2: Variation of $\mathbf{u}$ against $\mathbf{y}$

$\operatorname{Pr}=5, \mathrm{Gr}=10, \mathrm{Gm}=8, \mathrm{M}=2, \mathrm{~F}=0.5, \mathrm{Du}=0.03, \mathrm{~K}=1, \mathrm{Kr}=0.6$, $\mathrm{Sc}=3$.

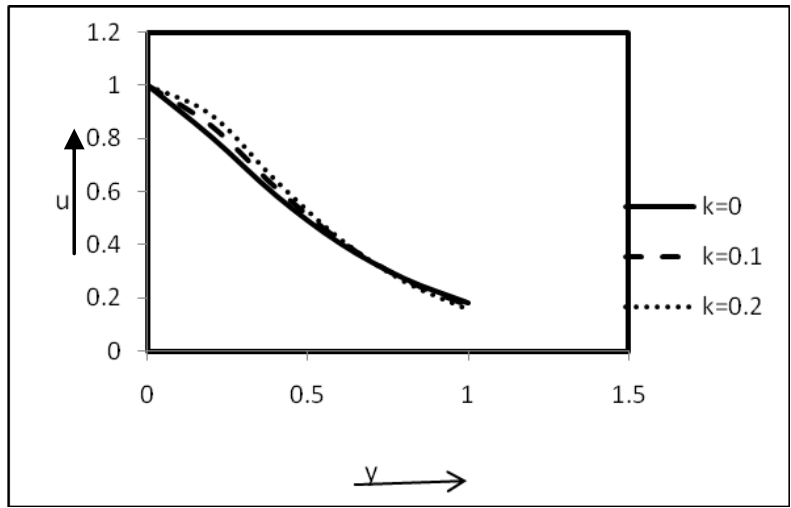

Figure 3: variation u against y

$\mathrm{Pr}=5, \mathrm{Gr}=5, \mathrm{Gm}=4, \mathrm{M}=2, \mathrm{~F}=0.5, \mathrm{Du}=0.03, \mathrm{~K}=1, \mathrm{Kr}=0.6$, $\mathrm{Sc}=3$.

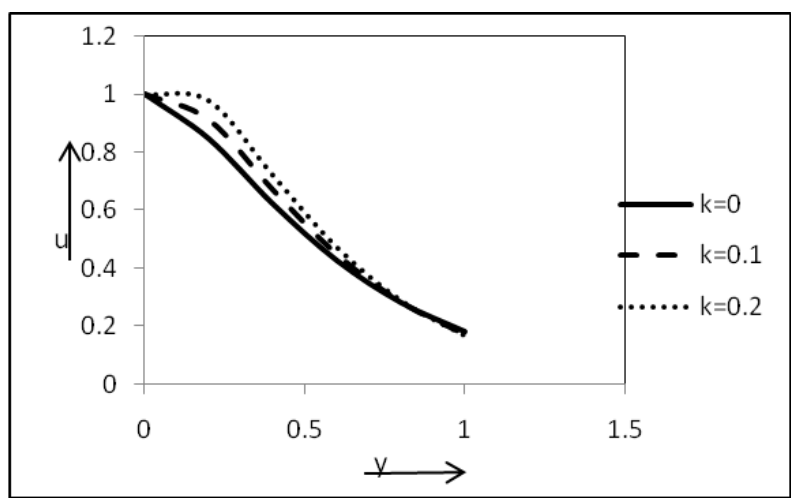

Figure 4: Variation of $u$ against $y$

$\mathrm{Pr}=5, \mathrm{Gr}=5, \mathrm{Gm}=8, \mathrm{M}=3, \mathrm{~F}=0.5, \mathrm{Du}=0.03, \mathrm{~K}=1, \mathrm{Kr}=0.6$, $\mathrm{Sc}=3$. 


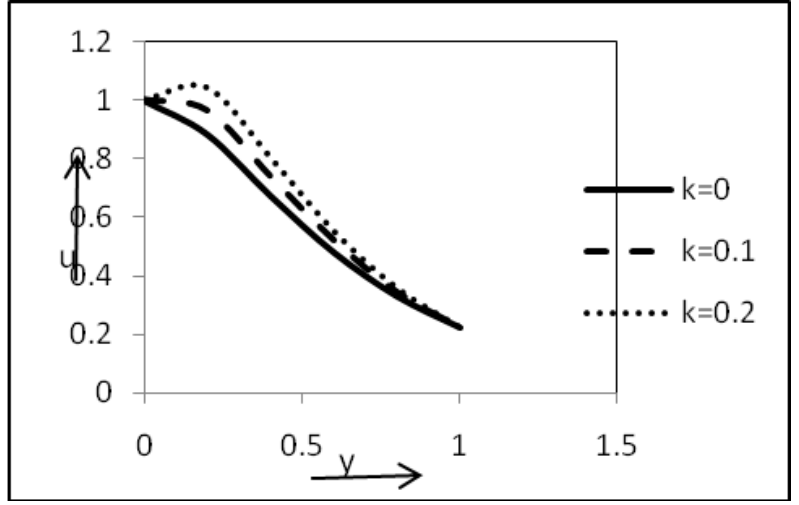

Figure 5: Variation of $u$ against $y$

$\mathrm{Pr}=5, \mathrm{Gr}=5, \mathrm{Gm}=8, \mathrm{M}=2, \mathrm{~F}=1.5, \mathrm{Du}=0.03, \mathrm{~K}=1, \mathrm{Kr}=0.6$, $\mathrm{Sc}=3$.

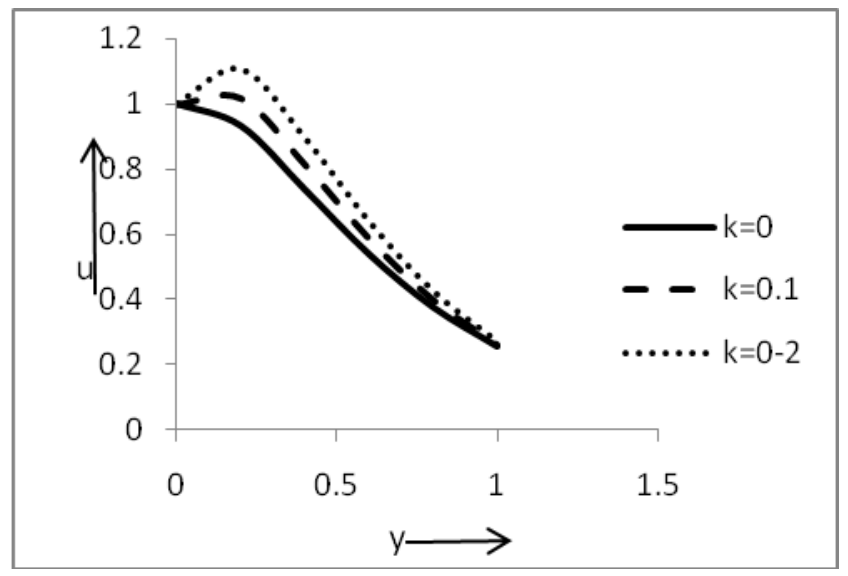

Figure 6: Variation of $u$ against $y$

$\mathrm{Pr}=5, \mathrm{Gr}=5, \mathrm{Gm}=8, \mathrm{M}=2, \mathrm{~F}=0.5, \mathrm{Du}=0.12, \mathrm{~K}=1, \mathrm{Kr}=0.6$, $\mathrm{Sc}=3$.

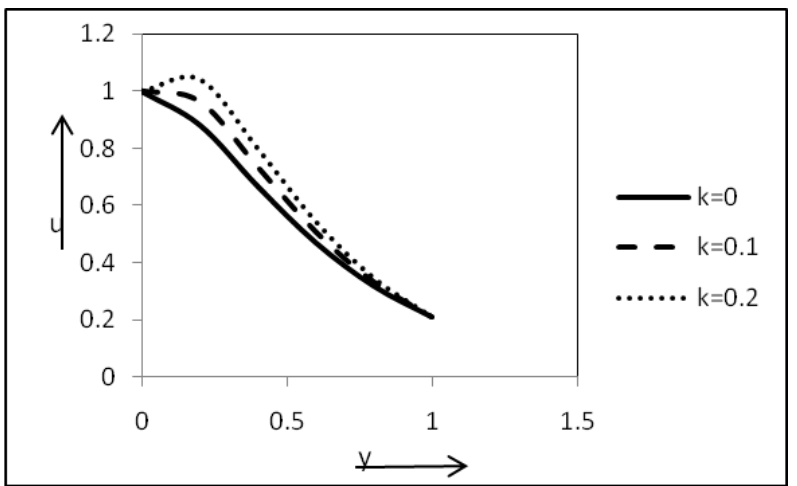

Figure 7: Variation of $u$ against $y$

$\mathrm{Pr}=5, \mathrm{Gr}=5, \mathrm{Gm}=8, \mathrm{M}=2, \mathrm{~F}=0.5, \mathrm{Du}=0.03, \mathrm{~K}=1, \mathrm{Kr}=1$, $\mathrm{Sc}=3$.

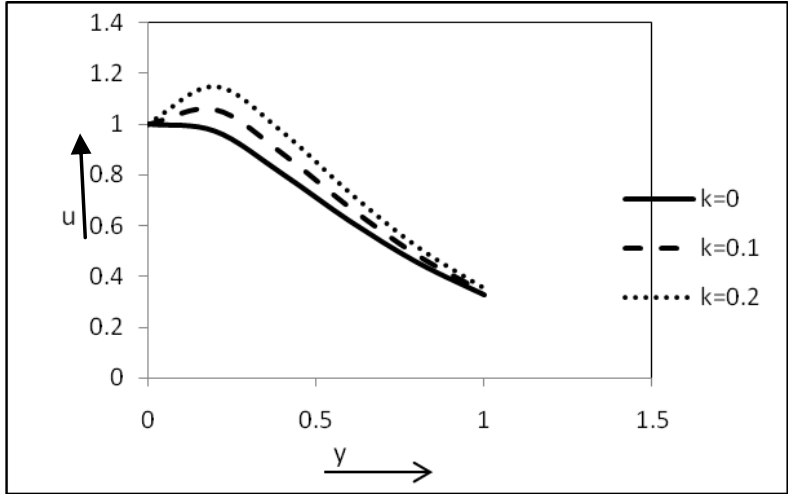

Figure 8: Variation of $u$ against $y$

$\mathrm{Pr}=5, \mathrm{Gr}=5, \mathrm{Gm}=8, \mathrm{M}=2, \mathrm{~F}=0.5, \mathrm{Du}=0.03, \mathrm{~K}=1, \mathrm{Kr}=0.6$, $\mathrm{Sc}=2$.

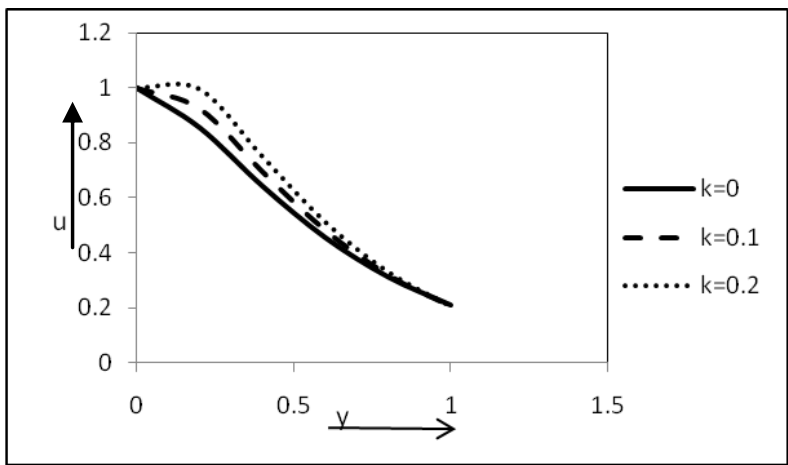

Figure 9: Variation of $u$ against $y$

$\operatorname{Pr}=10, \mathrm{Gr}=5, \mathrm{Gm}=8, \mathrm{M}=2, \mathrm{~F}=0.5, \mathrm{Du}=0.03, \mathrm{~K}=1$, $\mathrm{Kr}=0.6, \mathrm{Sc}=3$.

The figure10 depict the variation of flow past an externally heated plate $(\mathrm{Gr}<0)$. In this case, the fluid velocity shows a decelerating nature with the growth of visco-elasticity in compared to Newtonian fluid flow phenomena.

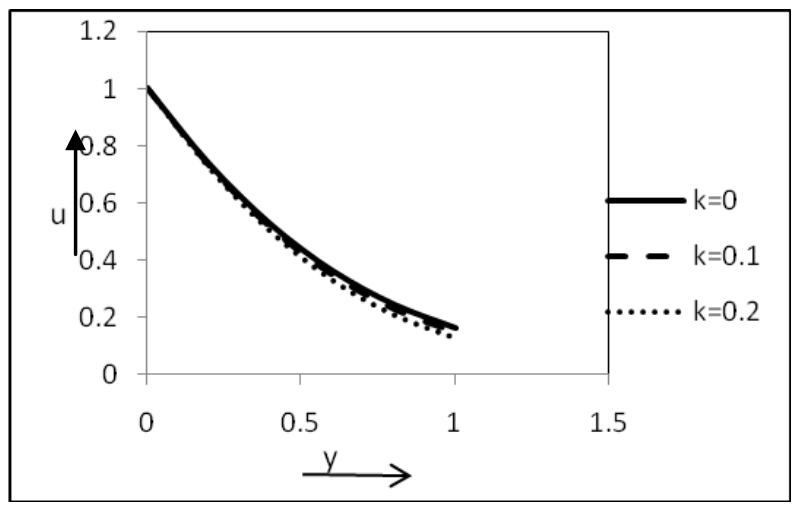

Figure 10: Variation of $u$ against $y$

$\mathrm{Pr}=5, \mathrm{Gr}=-5, \mathrm{Gm}=8, \mathrm{M}=2, \mathrm{~F}=0.5, \mathrm{Du}=0.03, \mathrm{~K}=1, \mathrm{Kr}=0.6$, $\mathrm{Sc}=3$. 
Figure 11 to 17 represent the shearing stress $\sigma$ against different significant flow parameters viz, Prandtl number Pr, Magnetic parameter $\mathrm{M}$, Dufour number $\mathrm{Du}$, chemical reaction parameter $\mathrm{Kr}$, Grashof number for heat transfer $\mathrm{Gr}$ and the radiation parameter $\mathrm{F}$.

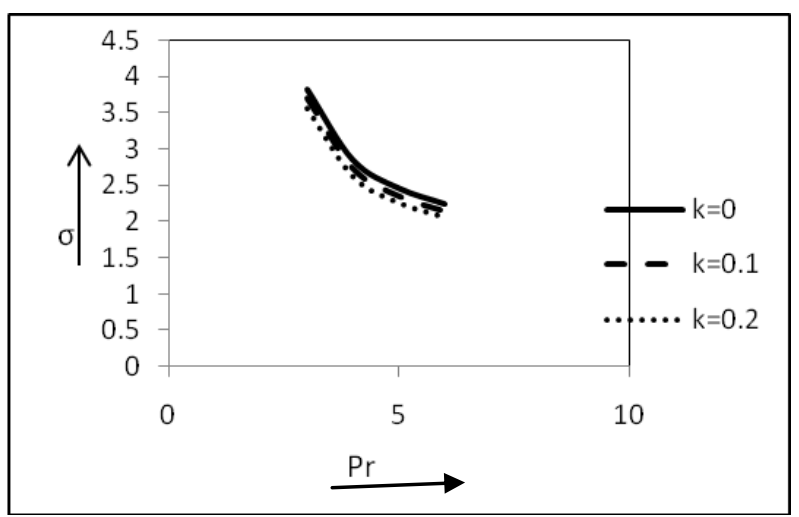

Figure 11: Variation of $\sigma$ against $\operatorname{Pr}$

Figure 11 illustrates the shearing stress at the plate against Prandtl number Pr. As Prandtl number increases viscous drag declines for both Newtonian and non-Newtonian parameter.

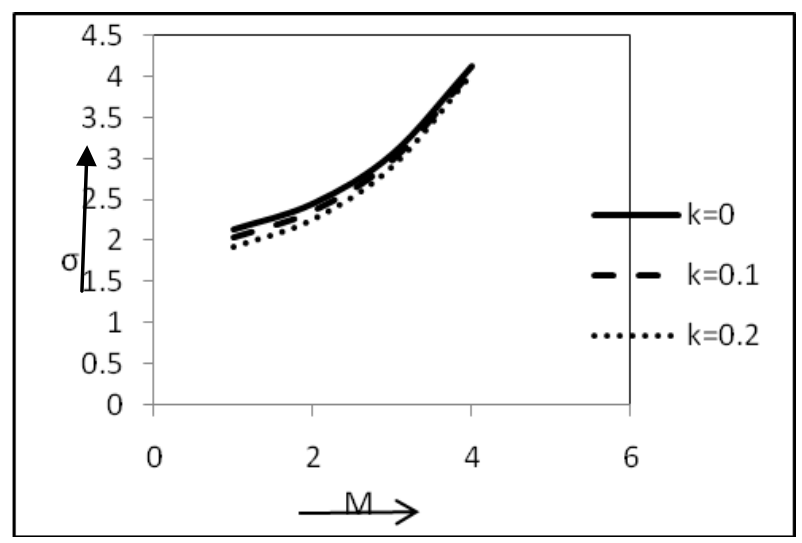

Figure 12: Variation of $\sigma$ against $\mathrm{M}$

Figure 12 shows the variation of shearing stress against Magnetic parameter (M).The figure reveals that the increasing values of Magnetic parameter amplifies magnitude of shearing stress.

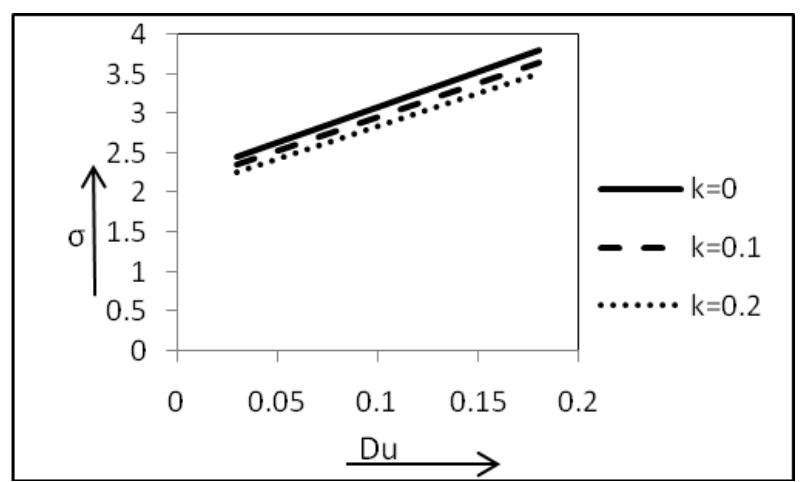

Figure 13: Variation of $\sigma$ against $\mathrm{Du}$
Figure 13 illustrates that the rising values of Dufour number increase the shearing stress for both Newtonian and nonNewtonian fluid flow phenomenon.

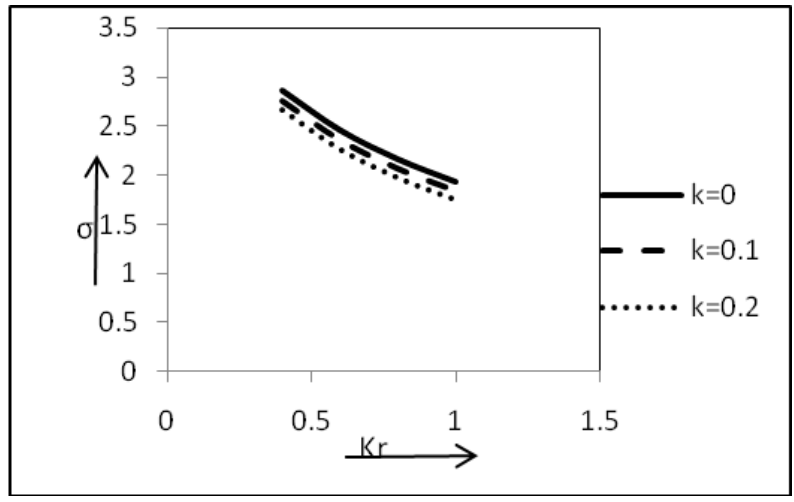

Figure 14: Variation of $\sigma$ against $\mathrm{Kr}$

Figure 14 illustrates the variation of shearing stress against chemical reaction $\mathrm{Kr}$. The figure shows that the growth of visco-elastic parameter subdues the shearing stress.

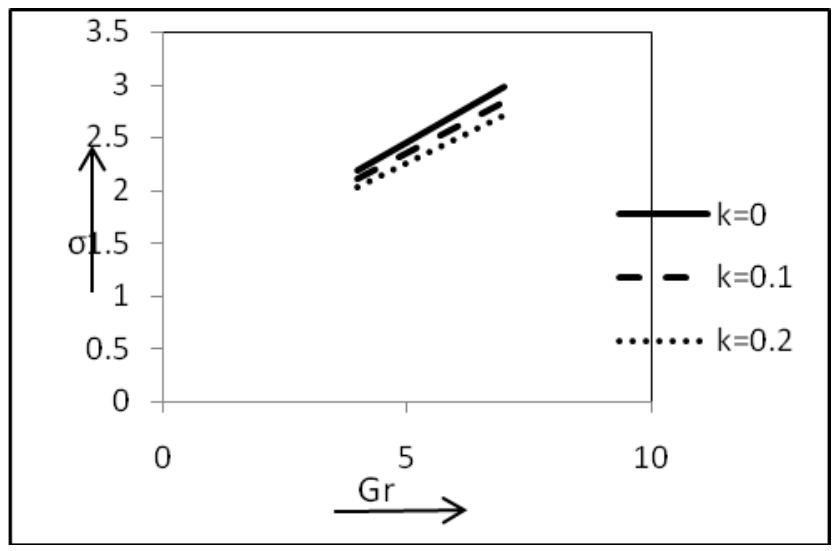

Figure 15: Variation of $\sigma$ against $\mathrm{Gr}$

Figure 15 shows that the magnitude of shearing stress decreases with amplified values of Grashof number for cooling plate $(\mathrm{Gr}>0)$

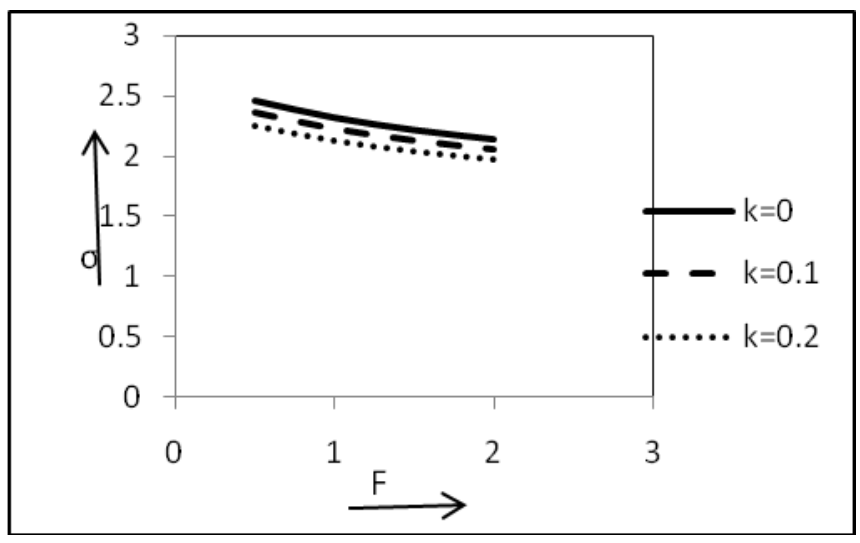

Figure 16: Variation of $\sigma$ against $F$

Figure 16 illustrates that as the Radiation parameter $\mathrm{F}$ increases, the shearing stress diminishes with the rise of visco-elastic parameter. 


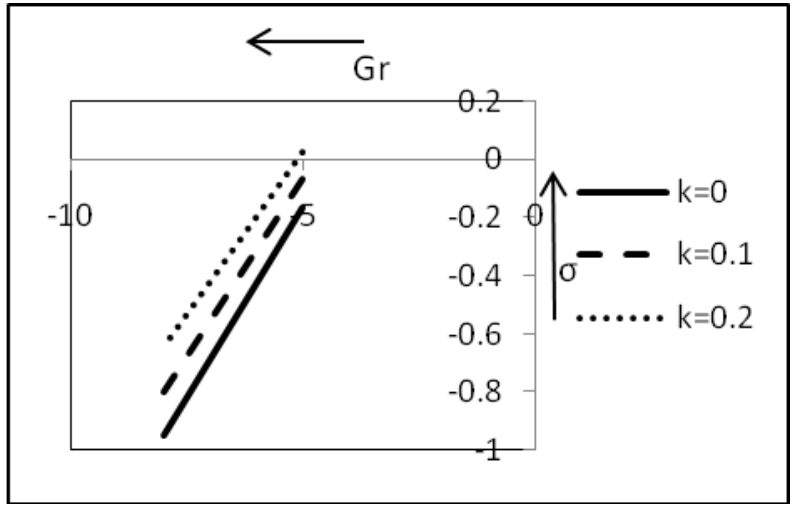

Figure 17: Variation of $\sigma$ against Gr

The variation of shearing stress against $\mathrm{Gr} \quad(\mathrm{Gr}<0)$ for heated plates depicted in figure 17. In this cases the magnitude of the shearing stress increases with the growth of visco-elasticity.

\section{CONCLUSION}

The MHD unsteady free convective visco-elastic fluid flow over a radiative vertical porous plate with Dufour effect in presence of chemical reaction and mass transfer has been investigated. From this study, we make the following conclusions :

(1) The velocity field is considerable affected by the viscoelastic parameter in presence of other flow parameters at all points of the fluid flow region.

(2) The fluid velocity exhibits an accelerating trend with the growing effect of visco-elasticity for externally cooled plate but an opposite trend is observed for externally heated plate.

(3) The effect of visco-elastic parameter on the shearing stress in prominent in the variation of other flow parameters.

(4) The temperature and concentration fields are not significantly affected by the visco-elastic parameter.

\section{REFERENCES}

[1]. D.A. Nield and A. Bejan, convection in porous media $2^{\text {nd }}$ edition, Springer-verlag, Berlin, 1998 .

[2]. P.L.Chambre, J.D.Young, on the diffusion of a chemically reactive species in laminar boundary layer flow, Physics of Fluids, 1 (1958), 48-54.

[3]. S.P.Anjali Devi, R Kandasamy, Effects of chemical reaction, heat and mass transfer for a non-linear MHD laminar boundary layer flow over a wedge with suction or injection, Int. Comn. Heat Mass Transfer 29(5), 2002, 707-716

[4]. A . Raptis, C Perdikis, Viscous flow over a non-linearly stretching sheet in the presence of a chemical reaction and magnetic field , Int. J . Non-linear Mech , 41 (2000), 527-529.

[5]. L. Mingchun, W . Yusheng, T . Yanwen, Z . Yuchun, Non-thermal equilibrium model of the coupled heat and mass transfer in strong endothermic chemical reaction system of porous media , Int. J. Heat Mass Transfer, 50 (2007) , 2936-2943.
[6]. R .Kandasamy, K . Periasamy, K.K.S Prabhu , Effect of chemical reaction, heat and mass transfer along a wedge with heat source and concentration in the presence of suction or injection, on MHD flow over a vertical stretching surface with heat source and thermal stratification effects. , Int. J. Heat Mass Transfer, 48 (2005) , 1388-1394.

[7]. F.S. Ibrahim , A. M. Elaiw, A.A.Bak, Effect of the chemical reaction and radiation absorption on the unsteady MHD free convection flow past a semi-infinite vertical permeable moving plate with heat source and suction, Communication in Non-linear Science and Numerical simulation.13 (6) 2008 , 1056-1066.

[8]. V . Rajesh and S.V.K. Verma, chemical reaction and radiation effects on MHD flow past an infinite vertical plate with variable temperature, Far East Journal of Mathematical Sciences, 32 (1), 2009 , 87-106.

[9]. K . Raveendra Babu , A.G.V Kumar and S.V.K Varma ; Diffusion -thermo and radiation effects on MHD free convective heat and mass transfer flow past an infinite vertical plate in the presence of a chemical reaction of first order, Advances in Applied Science Research , 3 (4) , 2012, 2446-2462.

[10]. S . S. Saxena and G . K. Dubey, Heat and mass transfer effects on MHD free convection flow of a visco-elastic fluid embedded in porous medium with variable permeability in the presence of radiation and heat source in slip flow regime, Advances in Applied Science Research , 2(5), 2011, 115-126.

[11]. R . Choudhury and M . Mahanta , Mixed convective MHD flow of visco-elastic fluid past a vertical infinite plate with mass transfer, Int. Journal of Scientific and Engineering Research , 3 (2) , 2012, 1-7.

[12]. R . Choudhury and U . J . Das, Visco-elastic effects on free convective three dimensional flow with heat and mass transfer, ISRN computational Mathematics, Ar ID 402037,8 pages , doi: 10 , 5402/2012/402037.

[13]. R . Choudhury and S . Purkayastha , Elastico-viscous effects on an oscillatory heat and mass transfer flow past a vertical plate with thermal diffusion and periodic suction velocity, Int. Journal of Advanced Scientific and Technical Research : 2 (5) , 2012, 215-232.

[14]. R . Choudhury and D . Dey, Mixerd convective MHD flow with heat and mass transfer of an elastic-viscous fluid from a vertical surface with ohmic heating in presence of radiation, Journal of fluids and thermal Sciences , 1 (2) , 131-143, 2012.

[15]. R . Choudhury and D. Dey, Free convective elasticviscous fluid flow with heat and mass transfer past an inclined plate in slip flow regime, Latin American Applied Research , 42 (4) 2012 , 327-332.

[16]. R . Choudhury and P . Dhar, Diffusion thermo effects of visco-elastic fluid past a vertical porous surface in presence of magnetic field and radiation , Int. Journal of Innovative Research in Science, Engineering and Technology, 2 (3) , 2013, 805-812. 